\title{
Management of early breast cancer in older women: from screening to treatment
}

\author{
This article was published in the following Dove Press journal: \\ Breast Cancer:Targets and Therapy \\ 7 July 2015 \\ Number of times this article has been viewed
}

\section{Fadwa Elomrani' \\ Maryem Zine ${ }^{2}$ \\ Mohamed Afif ${ }^{3}$ \\ Saad L'annaz' \\ Imane Ouziane' \\ Hind Mrabti' \\ Hassan Errihani'}

'Department of Medical Oncology, National Institute of Oncology,

${ }^{2}$ Department of Onco Hematology, Military Hospital Mohamed V,

${ }^{3}$ Department of Radiotherapy, National Institute of Oncology,

Rabat, Morocco
Correspondence: Fadwa Elomrani Department of Medical Oncology, National Institute of Oncology,

Avenue Allal Fassi, Ryad, Rabat, Morocco

Email elomranifadwa@gmail.com
Background: Breast cancer is a common condition. It is a leading cause of death among women, and its incidence increases with age. Aging of the population and improvement of the quality of life of elders make it a major public health issue. We reviewed the literature to try to determine the management of breast cancer in older women.

Methods: We conducted a narrative review by literature searches using key words "breast cancer", "elderly and older", and "women" in Pubmed, Scopus, and Google Scholar. The aim of this review is to summarize the management of early breast cancer in older women by discussing the controversies of screening in older women. Then, we try to define the optimal strategy for these women, either surgery alone or primary endocrine therapy. We also discuss the indications of lymph node dissection, and we evaluate the benefit of adjuvant radiotherapy, chemotherapy, and the anti HER2 treatment for these women.

Results: More than $50 \%$ of patients with breast cancer are 65 years or older, and around $30 \%$ are more than 70 years old. Most randomized trials did not include older women. Hence, the treatment of breast cancer in older patients is based on the management provided to younger women. Regardless of age, the treatment must aim for the best efficiency. Advanced age in itself should not be a limitation to treatment. There are no standard guidelines set for elderly patients. Surgical treatment for older patients evolved to avoid mastectomy, and conservative mammary surgery was proposed, similar to that used in younger patients. The proportion of elderly patients receiving adjuvant radiotherapy is increasing. The role of adjuvant radiotherapy in older patients with breast cancer was analyzed. Adjuvant chemotherapy is beneficial to women with hormone receptor-negative tumors. In those with hormone receptor-positive tumors, adjuvant chemotherapy in association to trastuzumab is beneficial for HER2-positive tumors, and for women with HER2-negative tumors adjuvant hormonal therapy is a very good option.

Conclusion: Breast cancer is common in older women. This population requires particular and adapted management. It is essential for older patients to be included in new clinical trials for individualized treatment recommendation.

Keywords: breast cancer, elderly women, chemotherapy, surgery, radiotherapy, hormonal therapy

\section{Introduction}

Breast cancer is a common condition. It is a leading cause of death among women, and its incidence increases with age. Aging of the population and improvement of the quality of life of elders make it a major public health issue.

More than $50 \%$ of patients with breast cancer are 65 years or older, and around $30 \%$ are more than 70 years old..$^{1-3}$ In Table 1, we show the incidence and the mortality of breast cancer in France. 
Table I The incidence and the mortality of breast cancer in France

\begin{tabular}{lll}
\hline Age (years) & Incidence/ I 00,000 & Mortality/ I 00,000 \\
\hline $60-64$ & 299.8 & 61.3 \\
$65-69$ & 386.1 & 73.4 \\
$70-74$ & 341.8 & 84.6 \\
$75-79$ & 295.8 & 101.2 \\
$80-84$ & 304.4 & 132.6 \\
$85-89$ & 338 & 183 \\
$90-94$ & 283.6 & 273.9 \\
$>95$ & 255.3 & 309.9 \\
\hline
\end{tabular}

A noncompliance with treatment, the existence of comorbidities that can affect mortality, and the high cost weighed against the expected poor benefits in this population are all factors that explain why most of the screening strategies do not include patients over 70 years of age. The result is that the diagnosis of breast cancer is often made late, and about $48 \%$ of patients over 65 years of age have metastases at the time of diagnosis. ${ }^{4}$

We performed a review of the literature to identify risk factors of breast cancer in women over 65 years old to determine the benefits and disadvantages of screening mammography in patients aged above 75 years. This review found that age is the main risk factor to develop breast cancer and die of it. This risk increases in cases of late first pregnancy, no history of breast-feeding, delayed menopause, hormonal replacement therapy, and postmenopausal overweight.

Randomized trials studying advantages of screening mammography have excluded women aged above 74 years. Thus, the benefits of screening this category of the population are unknown. However, observational studies suggest that older women with a life expectancy of more than 10 years should be included in mammography-based screening policies. These studies estimate that the mortality is reduced by $0.2 \%$ when women aged above 70 years undergo 2 yearly screening mammographies for 10 years rather than discontinuing this test at the age of $69 .{ }^{5}$

In a review by Marmot et al, ${ }^{6}$ the panel encouraged breast cancer screening in the UK because it reduced breast cancer mortality by $20 \%$ in 10,000 UK women aged $50-70$ years invited for screening mammography every 3 years. About 681 cancers were diagnosed and 43 deaths were prevented, but 129 represented an overdiagnosis. The choice between the benefits and harms of screening should be shared with women who agreed to be screened. ${ }^{6}$

The screening definitely has benefits such as reducing breast cancer mortality, but expert opinions are different from one country to another. Some find that the benefit is minimal, against a non-negligible overdiagnosis, which presents a source of anxiety for women.

In our opinion, the benefits and harms of screening should be discussed with women who agree to be screened and their choices should be respected.

Age does not affect histologic features of breast cancer. However, lobular, mucinous carcinomas are slightly more common in older women. These are usually small, slowproliferating, and low-grade tumors with positive hormonal receptors, negative HER2, and normal p53.7,8

\section{Discussion}

\section{Treatment of early breast cancer in older women}

Most randomized trials did not include older women, and prospective studies in this category are scarce. Hence, the treatment of breast cancer in older patients is based on the management of younger women. Currently, for every patient over 70 years of age presenting with breast cancer, a multidimensional geriatric assessment, including an accurate history, a clinical examination, and a comprehensive biological workup, is necessary to assess the patient's nutritional state; their mental, psychological, physical, and social autonomy; their independence; and their comorbidities, and thus to adapt the management. ${ }^{9}$

Recently, Audisio and Wyld ${ }^{10}$ reported that treatment of breast cancer in older women is not standard. In this editorial they discuss the choice between primary endocrine therapy and surgery for older women with breast cancer ER+ (estrogen receptor-positive). Four factors should be taken into consideration: anesthesiological contraindications; surgeon's preference; patient's preference; input from family, carers and friends. But, Audisio and $\mathrm{Wyld}^{10}$ concluded that none of these factors is robust enough to make a decision.

\section{Surgery}

Regardless of age, the treatment must aim for the best efficiency. Whenever possible, the management of breast cancer in older women should be similar to that in younger patients. Advanced age in itself should not be a limitation to treatment.

There are no standard guidelines set for older patients, and the management is different from one country to another and from one center to another. An international study comparing local treatments (surgery and radiotherapy) for operable breast cancer in older women included 204,885 patients across different countries. In many countries, most patients had undergone conservative surgery, with the highest proportion 
in Switzerland. The most striking conclusion drawn was that a large number of patients did not undergo any surgical intervention and that the likelihood to benefit from surgery for breast cancer diminished with increasing age. In all countries, an advancing age was also associated with less radiotherapy after tumorectomy. Moreover, older women treated for breast cancer underwent less axillary dissections. This study showed that despite large differences in managing older women with breast cancer, the survival was similar across all countries. ${ }^{11}$

Over the last 2 decades, studies were conducted with the aim of determining advantages and disadvantages of surgery and neoadjuvant hormonal therapy (Table 2). ${ }^{12-21}$ Two randomized controlled trials ${ }^{12,13}$ showed better locoregional control in favor of the surgical group, although results were not statistically significant. However, there was no survival benefit in either the tamoxifen-only or the surgery-only group. Similar results have been obtained by the Cancer Research Campaign UK when it compared tamoxifen only, to surgery followed by tamoxifen, in women aged 70 years or over with operable breast cancer. ${ }^{16}$ The Greta study compared tamoxifen as a primary treatment for operable breast cancer, with surgery followed by adjuvant tamoxifen, in women over 70 years of age and showed no difference in terms of survival. ${ }^{15}$

Recently, a Cochrane review conducted by Hind et a $1^{17}$ assessed the clinical efficacy of hormonal treatment as the sole treatment in operable breast cancer in women aged 70 years or above. No significant difference could be shown between primary hormonal therapy and surgery in terms of mortality. However, this review did demonstrate a longer survival without progression in favor of surgery, with or without hormonal therapy. ${ }^{17}$ Although surgical management seems to offer better local control, primary hormonal therapy can be an alternative for women with breast cancer expressing estrogen receptors and for whom surgery is not an option, either because of refusal or contraindication. ${ }^{17,18}$

\section{Axillary lymph nodes dissection}

In patients with breast cancer, the spread to axillary lymph nodes is a major prognostic factor that affects the therapeutic management. ${ }^{22}$ Axillary lymph nodes dissection (ALND) has minimal curative role, and its potential advantages are largely debated. While some studies show longer survival for patients undergoing axillary dissection, ${ }^{23}$ others failed to show any benefit. ${ }^{24}$

The American College of Surgeons Oncology Group (ACOSOG, Durham, NC, USA) conducted a prospective randomized trial, Z11, comparing axillary dissection vs no axillary surgery in women with $\mathrm{T} 1$ and $\mathrm{T} 2$ invasive breast cancer and 1-2 sentinel lymph node (SLNs), all undergoing lumpectomy and tangential whole-breast irradiation. The Z11 trial showed no significant difference in locoregional recurrence, after a median follow-up of 6.3 years. The risk of cancer recurring in the lymph nodes was $0.4 \%$ in groups who had the surgery and $0.9 \%$ in groups without axillary dissection, with less morbidity. There was no survival difference between the two groups. ${ }^{25}$

ALND may also be a cause of morbidity in older women (lymphedema, parethesias, adhesive capsulitis, etc) or may worsen a preexisting disability. ${ }^{26}$ In order to reduce the number of patients undergoing unnecessary ALND, axillary ultrasound and fine-needle aspiration of suspicious lymph

Table 2 Summary of different studies comparing surgery \pm hormonal therapy in older women

\begin{tabular}{|c|c|c|c|c|c|}
\hline Name of study & $\begin{array}{l}\text { Number of } \\
\text { patients included }\end{array}$ & Study design & $\begin{array}{l}\text { Median duration } \\
\text { of survival (years) }\end{array}$ & $\begin{array}{l}\text { Progression-free } \\
\text { survival }\end{array}$ & Overall survival \\
\hline EORTC I085I (UK) & 164 & Surgery vs tamoxifen $20 \mathrm{mg} / \mathrm{d}$ & 10 & $63 / 82$ vs $69 / 82^{\#}$ & $60 / 82$ vs $50 / 82^{\#}$ \\
\hline$\left(\right.$ Fentiman et $\left.\mathrm{al}^{14}\right)$ & & & & HR: 0.55 & HR: I.II $(0.75-I .65)^{\$}$ \\
\hline Nottingham (UK) & $|3|$ & Surgery vs tamoxifen $40 \mathrm{mg} / \mathrm{d}$ & 5 & $56 / 65$ vs $57 / 66^{\#}$ & $28 / 65$ vs $28 / 66^{\#}$ \\
\hline (Robertson et $\mathrm{al}^{12}$ ) & & & & HR: not estimated & HR: $1.06(0.59-1.92)^{\$}$ \\
\hline St Georges (UK) & 200 & Surgery vs tamoxifen $20 \mathrm{mg} / \mathrm{j}$ & 6 & $60 / 100$ vs $70 / 100^{\#}$ & $28 / 100$ vs $33 / 100^{\#}$ \\
\hline$\left(\right.$ Gazet et $\left.\mathrm{al}^{\left.\right|^{13}}\right)$ & & & & HR: not estimated & HR: $0.75(0.44-1.26)^{\$}$ \\
\hline CRC (UK) & 455 & Surgery plus tamoxifen $40 \mathrm{mg} / \mathrm{j}$ vs & 13 & Not reported & $159 / 225$ vs $187 / 230^{\#}$ \\
\hline$\left(\right.$ Fennessey et $\left.\mathrm{al}^{20}\right)$ & & tamoxifen only & & & HR: $0.78(0.63-0.96)^{\$}$ \\
\hline GRETA (Italy) & 274 & Surgery plus radiotherapy plus & 7 & $140 / 239$ vs $188 / 235^{\#}$ & $\mid 30 / 239$ vs $\mid 44 / 235^{\#}$ \\
\hline (Mustacchi et al ${ }^{15}$ ) & & tamoxifen $20 \mathrm{mg} / \mathrm{d}$ vs tamoxifen only & & HR: $0.65(0.53-0.8 I)^{\$}$ & HR: $0.98(0.77-1.25)^{\$}$ \\
\hline Naples (Italy) & 75 & Surgery plus radiotherapy plus tamoxifen & 10 & $9 / 38$ vs $13 / 37^{\#}$ & I2I months vs 123 \\
\hline \multirow[t]{2}{*}{ (Capasso et $\mathrm{al}^{21}$ ) } & & $20 \mathrm{mg} / \mathrm{d}$ vs tamoxifen only $160 \mathrm{mg} / \mathrm{d}$ then & & $P=0.4594$ & months \\
\hline & & $20 \mathrm{mg} / \mathrm{d}$ until progression & & & $P=0.8$ \\
\hline Nottingham.2 (UK) & 147 & Surgery plus tamoxifen vs tamoxifen & 5 & Not reported & $8 / 53$ vs $14 / 94^{\#}$ \\
\hline$\left(\right.$ Willsher et $\left.\mathrm{al}^{19}\right)$ & & $20 \mathrm{mg} / \mathrm{j}$ & & & HR: $0.80(0.73-2.32)^{\$}$ \\
\hline
\end{tabular}

Notes: "Number of patients who have progressed by the total number of patients included in each arms of the study; $\$$ data are expressed in months, and values in parentheses indicate the confidence interval of hazard ratio.

Abbreviation: HR, hazard ratio; d, day. 
nodes are usually performed preoperatively. When negative, sentinel lymph node technique seems to be a promising option to rule out any metastases. ${ }^{27}$

\section{Adjuvant chemotherapy}

Older patients with breast cancers were often excluded from clinical trials. An Oxford review of literature ${ }^{28}$ showed that polychemotherapy presents significant benefits in terms of survival and remission for patients younger than 70 years. However, these advantageous effects seem to diminish with increasing age. ${ }^{28}$

Unfortunately, only 600 women aged 70 years or above were included in the 47 analyzed trials of adjuvant chemotherapy, which makes estimating benefits of chemotherapy in this category impossible. ${ }^{29}$ Many patients with breast cancer are 70 years old or older, and with the aging of the population, it is expected that their numbers will increase even more. ${ }^{28}$

Consequently, there is obviously an urgent need to evaluate adjuvant chemotherapy in older patients. Adjuvant chemotherapy has been shown to be consistently beneficial only for younger patients. In a meta-analysis, adjuvant chemotherapy improved overall survival in patients aged between 50 and 69 years of age, regardless of the estrogen receptor status. ${ }^{30}$ However, because of the small number of patients over 70 years of age $(n=1,200)$ and the heterogeneity of both the disease and treatments, no definitive conclusions could be drawn.

In addition, two large observational studies suggested that adjuvant chemotherapy could be of benefit only to patients over 65 years of age with estrogen receptor negative and positive lymph nodes. ${ }^{31,32}$ Muss et $\mathrm{ll}^{33}$ conducted a randomized controlled trial with the aim of demonstrating the noninferiority of capecitabine to standard chemotherapy (CMF: cyclophosphamide, methotrexate and fluorouracil or AC: doxorubicin and cyclophosphamide) in women over 65 years of age with breast cancer. The results showed that capecitabine was inferior to standard chemotherapy in terms of relapse-free survival (3 years survival without relapse of $68 \%$ vs $85 \%$; HR: 2.09 , $P<0.001$ ) and overall survival (3 years overall survival $86 \%$ vs $91 \%$; HR: $1.85, P=0.02)$. The subgroup analysis revealed a significant interaction between treatment and hormonal status. Standard chemotherapy was demonstrated to be superior to capecitabine in terms of overall survival only in patients with negative estrogen receptors. ${ }^{33,34}$

\section{Radiotherapy}

The proportion of older patients receiving adjuvant radiotherapy is increasing. Likewise, the number of patients undergoing conservative mammary surgery with no irradiation is increasing. Again, as older patients tend to be excluded from randomized trials, the database that includes patients receiving locoregional treatment is limited. ${ }^{35}$ In 2011, the Oxford review showed that adjuvant radiotherapy after conservative mammary surgery halves the risk of a first relapse in all age groups; although, the absolute benefit in "low-risk" older patients seems to be minimal. Recently, Hughes et $\mathrm{a}^{36}$ reported the results of the Cancer and Leukemia Group (CALGB, Leicester, UK), who reviewed 9,343 studies on the impact of radiotherapy in women aged over 70 years with breast cancer. In the group treated with radiotherapy and tamoxifen, the rate of survival with no locoregional relapse was $98 \%$ vs $90 \%$ in patients receiving tamoxifen only $(P<0.001)$, with no significant difference in overall survival. Following these results, treatment with tamoxifen only seems a reasonable alternative for these patients. ${ }^{36}$

\section{Adjuvant hormonal therapy}

Although only few data that include women aged over 70-75 years are available, adjuvant hormonal therapy is a reference treatment for postmenopausal women with hormonereceptor-positive breast cancer. The Early Breast Cancer Trialists' Collaborative Group (EBCTCG) meta-analysis, which included 3,700 women, confirmed that tamoxifen reduced the relapse rate by $28 \%$ and mortality by $21 \%$ in women aged 70 years or more. Nevertheless, it is important to note that among the patients included, there were only 726 women aged above 70 years who received tamoxifen over 2 years, with a reduction of annual risk of relapse of $42 \% \pm 8 \%$, and 186 patients who received it during 5 years, reducing the annual risk of relapse by $54 \% \pm 13 \% .{ }^{37}$ The reduction of the annual risk of mortality was $36 \% \pm 7 \%$ and $34 \% \pm 13 \%$, respectively. This difference was statistically not significant, and, consequently, the effect of tamoxifen in this category of age did not seem to be related to the duration of treatment. However, the small number of the specimens refrain us from drawing any conclusion. Table $3^{38-41}$ shows the different studies comparing adjuvant hormonal therapy with tamoxifen vs placebo in older patients. The Breast International Group (BIG, Brussels, Belgium) 1-98 is a Phase III randomized double-blind study comparing four protocols of hormonal treatment over 5 years in postmenopausal women with hormone-receptor-positive breast cancer (group 1: letrozole only, group 2: letrozole followed by tamoxifen, group 3: tamoxifen only, group 4: tamoxifen followed by letrozole). A total of 8,010 women were assessed after a median followup of 25.8 months, and 351 events occurred in the letrozole 
Table 3 Summary of different studies comparing adjuvant hormonal therapy with tamoxifen vs placebo in older women

\begin{tabular}{|c|c|c|c|c|}
\hline Name of study & Study design & $\begin{array}{l}\text { Median duration } \\
\text { of follow-up }\end{array}$ & $\begin{array}{l}\text { Progression- } \\
\text { free survival }\end{array}$ & Overall survival \\
\hline Castiglone et $\mathrm{a}^{38}$ & $\begin{array}{l}\text { the study included } 320 \text { patients aged } \\
\text { between } 66 \text { and } 80 \text { years. They received } \\
\text { Tamoxifen } 20 \mathrm{mg} / \text { day and prednisone }\end{array}$ & 96 months & $\begin{array}{l}36 \% \text { vs } 22 \% \\
P=0.004\end{array}$ & $\begin{array}{l}49 \% \text { vs } 42 \% \\
P=0.43\end{array}$ \\
\hline Crivellari et $\mathrm{al}^{41}$ & $\begin{array}{l}349 \text { patients included aged between } \\
66 \text { and } 80 \text { years. Mastectomy followed by } \\
\text { tamoxifen and prednisone vs no treatment }\end{array}$ & 21 years & $\begin{array}{l}\text { Improvement of } \\
\text { progression free } \\
\text { survival }(P=0.003)\end{array}$ & $\begin{array}{l}\text { Improvement of I } 5 \text { years } \\
\text { overall survival and relapse-free } \\
\text { survival, } 10 \% \pm 3 \% \text { vs } 19 \% \pm 3 \% \\
\mathrm{HR}, 0.71 ; \$ 95 \% \mathrm{Cl}, 0.58 \text { to } 0.86^{\$}\end{array}$ \\
\hline Mouridsen et $\mathrm{a}^{40}$ & $\begin{array}{l}509 \text { patients included were } 70 \text { years old } \\
\text { or more tamoxifen and local irradiation vs } \\
\text { irradiation only }\end{array}$ & 6 years & $\begin{array}{l}48 \% \text { vs } 39 \% \\
P=0.0008\end{array}$ & No difference in overall survival \\
\hline Cummings et $\mathrm{a}^{39}$ & $\begin{array}{l}\text { I8I patients included were } 65-84 \text { years } \\
\text { old tamoxifen over } 2 \text { years vs placebo }\end{array}$ & 10 years & $\begin{array}{l}7.4 \text { vs } 4.4 \text { years } \\
P=0.00 I\end{array}$ & $\begin{array}{l}8.5 \text { vs } 8 \text { years } \\
P=0.063\end{array}$ \\
\hline
\end{tabular}

Note: ${ }^{\$}$ Data are expressed in months.

Abbreviations: $\mathrm{Cl}$, confidence interval; $\mathrm{HR}$, hazard ratio.

group and 428 occurred in the tamoxifen group. At 5 years, the disease-free survival rate reached $84 \%$ in the letrozole group and $81.4 \%$ in the tamoxifen group. Complications, which included venous thromboembolic complications, endometrial cancers, and vaginal bleeding, were more common in the tamoxifen group. On the other hand, women receiving letrozole suffered more hypercholesterolemia, cardiac events, and bone fractures. ${ }^{42}$ The Arimidex, Tamoxifen, Alone or in Combination (ATAC) trial, which compared anastrozole and tamoxifen in women over 65 years of age, with a small proportion of patients who were over 70 years, just $27 \%$ were included, revealed a benefit in favor of anastrozole by reducing recurrence at $9.7 \%$ in anastrazole arms vs $12.5 \%$ in tamoxifen arms at 5 years, but no effect of overall survival (OS) was noted. In the subgroup analysis, the advantage of anastrozole was mainly observed in patients who had not received any adjuvant chemotherapy and in those who had lymph node involvement, whereas in the BIG 1-98 trial, letrozole was more beneficial in patients having received chemotherapy and in those with lymph node metastasis. ${ }^{43}$

\section{Anti-HER2 therapy}

The prevalence of tumors overexpressing HER2 in women aged 70 years or more varies between $7 \%$ and $20 \%$. Up to now, data regarding efficacy and tolerance of trastuzumab in older patients are still scarce. Some retrospective series suggest that tolerance to trastuzumab is maintained in patients over 60 years of age. ${ }^{44-46}$ However, adjuvant trastuzumab trials revealed that the incidence of cardiac events increased with age and close cardiac follow-up is required. In addition, a recent Spanish retrospective study, which analyzed 45 patients over 70 years of age with locally advanced breast cancer who received trastuzumab, found that cardiac toxicity was more likely in patients with background of heart disease and/or diabetes. ${ }^{47}$ Finally, a cohort study that followed 9,535 patients with a median age of 70 years found that among the 2,203 patients who received trastuzumab, $29.4 \%$ developed congestive heart failure vs $18.9 \%$ for other patients $(P<0.001){ }^{48}$

\section{Conclusion}

Breast cancer is common in older women. This population requires particular and adapted management, hence the importance of informing practitioners about the necessity of a thorough geriatric assessment prior to any medical prescription. Importantly, integrating geriatric tools in prospective studies would allow a better understanding of tolerance and observance aspects related to different treatments.

\section{Acknowledgments}

We thank Dr Kamal Berchid for editorial support in the preparation of this manuscript.

\section{Disclosure}

The authors report no conflicts of interest in this work.

\section{References}

1. Binder-Foucard F, Bossard N, Delafosse P, Belot A, Woronoff AS, Remontet L. Incidence and mortality of cancer in France during the period 1980-2012: solid tumors. J Epidemiol Publ Health. 2013;62(2):95-108.

2. Yancik R, Ries LA. Cancer in older persons: an international issue in an aging world. Semin Oncol. 2004;31(2):128-136.

3. Jemal A, Clegg LX, Ward E, et al. Annual report to the nation on the status of cancer, 1975-2001, with a special feature regarding survival. Cancer. 2004;101(1):3-27.

4. Ries LAG, Eisner MP, Kosary CL. SEER Cancer Statistics Review. 1973-1999. Bethesda, MD: National Cancer Institute; 2009.

5. Walter LC, Schonberg MA. Screening mammography in older women: a review. JAMA. 2014;311(13):1336-1347. 
6. Marmot MG, Altman DG, Cameron DA, et al. The benefits and harms of breast cancer screening: an independent review. Br J Cancer. 2013; 108(11):2205-2240.

7. Diab SG, Elledge RM, Clark GM. Tumor characteristics and clinical outcome of elderly women with breast cancer. J Natl Cancer Inst. 2000;92: 550-556.

8. Berg JW, Hutter RV. Breast cancer. Cancer. 1995;75(S1):257-269.

9. Monfardini S, Ferrucci L, Fratino L, Del Lungo I, Serraino D, Zagonel V. Validation of a multidimensional evaluation scale for use in elderly cancer patients. Cancer. 1996;77:395-401.

10. Audisio RA, Wyld L. No standard is set for older women with breast cancer. Eur J Surg Oncol. 2015;41:607-609.

11. Kiderlen M, Bastiaannet E, Walsh PM, et al. Surgical treatment of early stage breast cancer in elderly: an international comparison. Breast Cancer Res Treat. 2012;132(2):675-682.

12. Robertson JF, Todd JH, Ellis IO, Elston CW, Blamey RW. Comparison of mastectomy with tamoxifen for treating elderly patients with operable breast cancer. BMJ. 1988;297:511-514.

13. Gazet JC, Ford HT, Coombes RC, et al. Prospective randomized trial of tamoxifen vs surgery in elderly patients with breast cancer. Eur J Surg Oncol. 1994;20:207-214.

14. Fentiman IS, Christiaens MR, Paridaens R, et al. EORTC treatment of operable breast cancer in the elderly: a randomised clinical trial EORTC 10851 comparing tamoxifen alone with modified radical mastectomy. Eur J Cancer. 2003;39:309-316.

15. Mustacchi G, Ceccherini R, Milani S, et al; Italian Cooperative Group GRETA. Tamoxifen alone versus adjuvant tamoxifen for operable breast cancer of the elderly: long-term results of the phase III randomized controlled multicenter GRETA trial. Ann Oncol. 2003;14:414-420.

16. Bates T, Riley DL, Houghton J, Fallowfield L, Baum M. Breast cancer in elderly women: a Cancer Research Campaign trial comparing treatment with tamoxifen and optimal surgery with tamoxifen alone. The Elderly Breast Cancer Working Party. Br J Surg. 1991;78: 591-594.

17. Hind D, Wyld L, Reed M. Surgery vs tamoxifen for operable primary breast cancer in older women: cochrane review. Br J Cancer. 2007;96: 1025-1029.

18. Biganzoli L, Wildiers H, Oakman C, et al. Management of elderly patients with breast cancer: updated recommendations of the International Society of Geriatric Oncology (SIOG) and European Society of Breast Cancer Specialists (EUSOMA). Lancet Oncol. 2012;13:e148-e160.

19. Willsher PC, Robertson JFR, Jackson L, Al-Hilaly M, Blarney RW. Investigation of primary tamoxifen therapy for elderly patients with operable breast cancer. Breast. 1997;6:150-154.

20. Fennessey M, Bates T, McRae K, Riley D, Houghton J, Baum M. Randomised trial of surgery plus tamoxifen vs tamoxifen-alone in women over age 70 with operable breast cancer. Br J Surg. 2004;91: 699-704.

21. Capasso I, Nuzzo F, Labonia V, Landi G, Rossi E, De Matteis A. Surgery and tamoxifen vs tamoxifen as treatment of stage I and II breast cancer in over to 70 years old women: ten years follow-up. Ann Oncol. 2000;11:20.

22. Fisher B, Bauer M, Wickerham D, Redmond CK, Fisher ER. Relation of number of positive axillary nodes to the prognosis of patients with primary breast cancer: an NSABP update. Cancer. 1983;52: 1551-1557.

23. Martelli G, Miceli R, Daidone MG, et al. Axillary dissection versus no axillary dissection in elderly patients with breast cancer and no palpable axillary nodes: results after 15 years of follow-up. Ann Surg Oncol. 2011;18:125-133.

24. Armando E, Giuliano, MD, Kelly K, et al. Axillary dissection vs no axillary dissection in women with invasive breast cancer and sentinel node metastasis: a randomized clinical trial. JAMA. 2011;305(6):569-575.

25. Petrek JA, Heelan MC. Incidence of breast carcinoma-related lymphedema. Cancer. 1998;83:2776-2781.
26. Hall SJ, Brown SE, Porter GRJ, et al. Axillary ultrasound in staging breast cancer: diagnostic accuracy and effect on subsequent axillary surgery - the Plymouth experience. Breast Cancer Res. 2009; 11(Suppl 2):21.

27. Syed A, Garbos M, Patel A, Bradpiece H, Stephanie J. Role of axillary ultrasound in defining surgical management of breast cancer patients with nodal disease. Cancer Res. 2009;69(24 Suppl).

28. Early Breast Cancer Trialists Collaborative Group (EBCTCG). Polychemotherapy for early breast cancer: an overview of the randomised trials. Lancet. 1998;352:930-942.

29. Biganzoli L, Goldhirsh A, Straehle C, et al. Adjuvant chemotherapy in elderly patients with breast cancer: a survey of the Breast International Group (BIG). Ann Oncol. 2004;15(2):207-210.

30. Early Breast Cancer Trialists' Collaborative Group (EBCTCG). Adjuvant chemotherapy in oestrogen-receptor-poor breast cancer: patient-level meta-analysis of randomised trials. Lancet. 2008;371:29-40.

31. Giordano SH, Duan Z, Kuo YF, et al. Use and outcomes of adjuvant chemotherapy in older women with breast cancer. J Clin Oncol. 2006;24:2750-2756.

32. Elkin EB, Hurria A, Mitra N, et al. Adjuvant chemotherapy and survival in older women with hormone receptor-negative breast cancer: assessing outcome in a population-based, observational cohort. J Clin Oncol. 2006;24:2757-2764.

33. Muss HB, Berry D, Constance T, et al. Adjuvant chemotherapy in older women with early-stage breast cancer. N Engl J Med. 2009;360(20): 2055-2065.

34. Jager A, Verweij J, Sleijfer S. Adjuvant chemotherapy in older patients with breast cancer. Nat Rev Clin Oncol. 2009;6(10):563-565.

35. Kunkler I. Radiotherapy issues in elderly breast cancer patients. Breast Care (Basel). 2012;7(6):453-459.

36. Hughes KS, Schnaper LA, Bellon JR, et al. Lumpectomy plus tamoxifen with or without irradiation in women age 70 years or older with early breast cancer: long-term follow-up of CALGB 9343. J Clin Oncol. 2013;31:2382-2387.

37. Early Breast Cancer Trialists' Collaborative Group (EBCTCG). Tamoxifen for early breast cancer: an overview of the randomized trials. Lancet. 1998;351:1451-1468.

38. Castiglione M, Gelber RD, Goldhirsh A. Adjuvant systemic therapy for breast cancer in the elderly: competing causes of mortality. J Clin Oncol. 1990;8(3):519-526.

39. Cummings FJ, Gray DC, Tormey TE, et al. Adjuvant tamoxifen versus placebo in elderly women with node-positive breast cancer: long-term follow-up and causes of death. J Clin Oncol. 1993;11(1):29-35.

40. Mouridsen HT, Andersen AP, Brincker H, et al. Adjuvant tamoxifen in post-memopausal high risk breast cancer patients: present status of Danish breast cancer cooperative group trials. NCI Monogr. 1985;1: 115-118.

41. Crivellari D, Price K, Richard D, et al. Adjuvant endocrine therapy compared with no systemic therapy for elderly women with early breast cancer: 21-year results of International Breast Cancer Study Group Trial IV. J Clin Oncol. 2003;21:4517-4523.

42. The Breast International Group (BIG) 1-98 Collaborative Group. A comparison of letrozole and tamoxifen in postmenopausal women with early breast cancer. N Engl J Med. 2005;353:2747-2757.

43. Baum M, Buzdar A, Cuzick J, et al. Anastrozole alone or in combination with tamoxifen versus tamoxifen alone for adjuvant treatment of postmenopausal women with early breast cancer: results of the ATAC (Arimidex, Tamoxifen, Alone or in Combination) trial efficacy and safety update analyses. Cancer. 2003;98:1802-1810.

44. Brunello A, Monfardini S, Crivellari D, et al. Multicenter analysis of activity and safety of trastuzumab plus chemotherapy in advanced breast cancer in elderly women (>70 years). J Clin Oncol. 2008;26(15): Abstract 1096.

45. Paton VE, Klein P, Lieberman G. Trastuzumab $(\mathrm{H})$ benefits both younger and older women with HER2 positive MBC. Proc Am Soc Clin Oncol. 2003;22:Abstract 294. 
46. Fyfe GA, Mass R, Murphy M, et al. Survival benefit of trastuzumab (Herceptin) and chemotherapy in older (age >60) patients. Proc Am Soc Clin Oncol. 2001;20:Abstract 189.

47. Serrano C, Cortés J, De Mattos-Arruda L, et al. Trastuzumab related cardiotoxicityin the elderly: a role for cardiovascular risk factors. Ann Oncol. 2012;23:897-902.
48. Chavez-MacGregor M, Zhang N, Buchholz TA, et al. Trastuzumabrelated cardiotoxicity among older patients with breast cancer. J Clin Oncol. 2013;31(3):4222-4228.

\section{Publish your work in this journal}

Breast Cancer: Targets and Therapy is an international, peerreviewed open access journal focusing on breast cancer research, identification of therapeutic targets and the optimal use of preventative and integrated treatment interventions to achieve improved outcomes, enhanced survival and quality of life for the cancer patient.
View the full aims and scopes of this journal here. The manuscript management system is completely online and includes a very quick and fair peer-review system, which is all easy to use. Visit http:// www.dovepress.com/testimonials.php to read real quotes from published authors.

Submit your manuscript here: http://www.dovepress.com/breast-cancer---targets-and-therapy-journal 